\title{
Assessing the Impact of Promotion-Related Conflicts on Faculty Productivity: A Case Study of Ghanaian Public Universities
}

\author{
Hagar Bampoh-Addo \\ Deputy Registrar \\ Division of Academic Affairs \\ University of Education, Winneba \\ Winneba, Ghana.
}

\begin{abstract}
Promotion-related conflict in the Universities presents a continuous challenge to administrators and affects faculty productivity in terms of the achievement of institutional goals and mandate. This study sought to investigate the impact of promotion-related conflicts and their resolution on faculty productivity in the Universities. As such, quantitative method of research was used for data collection and analysis. The target population of the study was all public universities in Ghana, specifically, their faculty and senior administrators. Descriptive and inferential analysis including One-Way ANOVA, Kruskal Wallis Test and Multiple regression were conducted on quantitative data using SPSS version 21. The major finding from the study was that promotion-related conflict in Higher Education Institutions has negative effects on both faculty and institutional performance depending on the nature of the conflict and how it is resolved. The study recommends that robust orientation pertaining to promotions should be given to both faculty members and senior administrators to minimize the occurrence of such conflicts.
\end{abstract}

Keywords: Promotion, Conflicts, Conflict Resolution, Faculty, Productivity.

\section{Background and the Problem}

The way and manner intra-organization conflicts are handled should be fully developed to enhance job performance and productivity. Globally, organizational conflicts are known to have impacts on individual employees and organizations at large. Conflict may arise due to differences in points of views, ideologies, institutional structures as well as unhealthy competition. Depending on how these conflicts are handled, they can lead to significant negative consequences on the general performance of the organisation of which Universities are no exception.

A common but less researched source of Higher Education Institutions (HEIs) conflict is promotion-related issues. Though it is expected that through promotion, organizational effectiveness and individual performance can be increased, job performance of staff sometimes fall below the expected levels due to how conflicts and issues are handled (Mills and Hyle, 1999). According to Mills and Hyle (1999) and Hart (2002), promotion issues could be emotional and if not properly handled, could affect staff commitment to work. As in any organization, job promotions in HEIs are expected to stimulate an improvement in the level of skills and talents of faculty members.

Gappa, Austin and Trice (2007) and Kczynski (2002) noted that it is through promotion, training and development activities that professionalism, productivity, organizational effectiveness and individual performance can be increased. In HEIs, a faculty is recognized through promotions that are based on evaluation reports (Hearn and Anderson, 2002). Faculty professional progression has therefore become an integral part in achieving institutional mandates and goals.

According to Billson (2000), an employee can get upset or demoralised because of an unpleasant promotion experience and this can result in non-cooperation at the workplace. Some faculty members do get disappointed when their colleagues with similar qualifications and experiences are promoted either due to favouritism or due to lack of systematic promotion policy implementation.

From the perspective of the Human Needs Theory, Burton (1990) asserts that faculty-promotion can be considered as an emotional process, as aforementioned, because it has to do with recognition or change in status as a need. In support of this perspective, Oforiwaa and Broni (2014) assert that Academic Faculty rankings as a way of recognition bring to fore the importance of promotions for faculty members in HEIs. They explain that this is because advancement in ranks comes with additional salary, increase influence within the university, recognition and leadership positions.

In Ghana, the higher education system has experienced several cases of instability over the past three decades mainly due to faculty conditions of service. Much of that is manifested in the form of staff strikes and tensions in both Polytechnics and Public (State-owned) Universities. 
Also, anecdotal evidence from the various institutions highlighted several cases where staff sued their institutions over promotion-related issues. Although it is generally expected that all universities have credible promotion policies with a Procedural Appeal System (PAS) as inbuilt conflict resolution mechanisms, there is little knowledge about how these operate in practice among faculty members since these institutions often fail to effectively communicate available promotion policies to staff.

Clue (2013) reported that promotion has been a worry to most staff. This creates lots of dissatisfaction among employees and impacts negatively on staff performance. Schnake (1987) explains that the absence of effective communication between groups or individuals representing different structural levels can trigger conflict within the group. Apart from communication issues with regards to promotion guidelines, are issues such as favouritism on the part of administrative leaders in the processing of documents submitted by faculty for promotions. An attempt on the part of an applicant or administrative leaders to flout established policies or guidelines for promotions could create a kind of promotion-related conflict (P-RC) that can result in low morale and motivation, stress, resentment and even strained interpersonal relationships.

The few authors including Allen (1988), Tien and Blachburn (1996), Mills and Hyle (1999) who looked at faculty promotions, failed to investigate faculty promotion-related conflicts, their effects on faculty productivity and resolution mechanisms that exist within HEI. The review of the literature shows that the extant of literature does not discuss conflicts in terms of impacts on productivity as this study does. Most of these studies in Higher Education were based on either qualitative or quantitative designs - mainly reviews of literature and in-depth analysis of particular situations. They do not account for diversity of views across a variety of institutions and staff within them and hence are not generalizable. This current study adopts a quantitative approach to examine the issue in a more nuanced way. Of relevance to this research is that studies were not conducted within the Ghanaian context. Therefore, there is dearth of literature, this study hence, fills the gap by investigating the consequences of promotion-related conflicts and their resolution on faculty productivity. In order to achieve this objective, the study asks the question: 'To what extent do promotion-related conflicts and its resolution influence faculty productivity in Ghanaian public universities? The study tests the Null hypothesis: 'The faculty promotion modalities and procedures, the Nature of promotion-related conflict and the manner in which conflict is resolved do not influence Faculty productivity.

The rest of the paper is organised as follows: a brief review of relevant literature on the effects of conflict follows the background and the problem, the methodology and data issues are then discussed. The findings from the results of the quantitative analysis are then presented and discussed, a section of conclusion and recommendation then ends the study.

\section{Brief Literature Review}

\section{Effects of Conflicts}

Kittlaus and Leas (1978), argue that conflict leads to unfolding tempers and hidden positive and negative characteristics of an individual or a group of people. Their depiction of the effects of conflict on institutional performance is indicated in figure 1

Figure1: Effect of Conflict on Institutional Performance

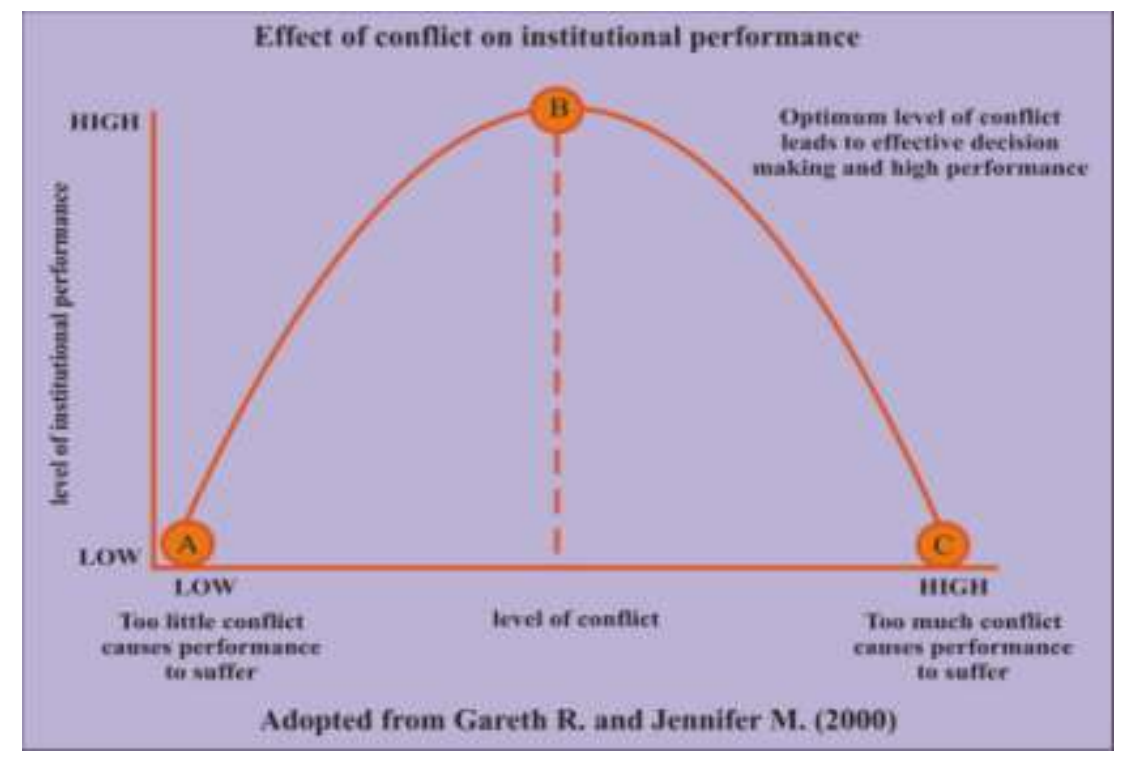


The figure suggests that institutional productivity suffers where there is conflict. The views of researchers concerning the impact of conflict on productivity vary. Some researchers are of the view that organizational conflicts impact positively on the organization, for instance, Hellriegel et al. (1992) contend that conflict in an institution can be a positive force. He argues that the creation or resolution of conflict often leads to constructive problem solving. The view is that the need to resolve conflict can cause people to search for ways of changing how to do things. The conflictresolution process is often a stimulus for positive change within an organization. The search for ways to resolve conflict may not only lead to innovation and change, but it may make changes more acceptable.

Thomas (1976) observes that confrontation of divergent views often produces ideas of superior quality. Divergent views are apt to be based upon different evidence, different considerations, different insights, and different frames of reference. Thomas further asserts that, there is a growing reason to believe (both from research and expert opinion) that conflict causes people to seek effective ways of dealing with it, resulting in improved organizational functioning, for instance, cohesiveness, clarified relationships and clearer problem-solving procedures.

Deutch (1973) also contends that a conflict within a group frequently helps to revitalize existent norms, or it contributes to the emergence of new norm. In this sense, social conflict is a mechanism for adjustment of norms adequate to new conditions. A flexible society benefits from conflict because such behaviour, by helping to create and modify norms, assures its continuance under changed conditions

According to Wright and Noe (1996), conflict can lead to positive results such as renewed motivation. They suggest that conflict permits the venting of frustration. Conflict can serve as an escape valve that allows the release of built-up emotions and negative feeling. They further argue that conflict can lead to personal growth and maturity. It implies that conflict could compel one to learn how to work more effectively with others in solving problems and resolving differences. This also suggests that we should consider conflict as an opportunity for learning, personal growth and progress in all endeavours.

Although few who really understand conflict would advocate its deliberate use in organizational life, few would eliminate or avoid it. Instead of seeking to eliminate all forms of conflict in an organization, it is rather beneficial to apply the concept of conflict management to minimize its destructive potential and make it as productive, creative and useful as possible (Owens, 1987).

Other researchers hold a different view that the effects of conflict are mainly negative. According to Aldag and Stearns (1987), anyone who has ever worked in an organization knows that conflict exists and that it can have destructive effects on the organization and the members' activities. This implies that conflict in the workplace can cause great stress and unhappiness and also lower outputs. In extreme cases, such conflicts can result in strike actions.

Barker and Gum (1994) emphatically state that, many times, in the midst of conflict, opposing individuals or groups will put their own interests or goals above those of the organization, resulting in the lessening of the organization's effectiveness. Owens (2001) also opines that frequent and powerful conflict can have a devastating impact on the behaviour of people in an organization, in that, conflict often develops into hostility which also causes people to withdraw both physically and psychologically. In the case of higher institutions of learning, physical withdrawal can take the form of absence and turnover of staff. This can also be related to Psychological withdrawal of the faculty in the form of alienation, apathy and indifference. On this score, some researchers opine that though a solution may be reached in conflict resolution, the means of gaining the solution may cause pain to the people involved and general weakening of relationships.

The literature reviewed so far suggest that the notion that conflict has negative effects and, thus should be eliminated does not wholly give the right impression. Subsequently, in recent times, conflict has been given a different dimension resulting in the idea that conflict is neither inherently good nor bad but simply inevitable wherever people are found. It should be accepted that too much conflict can have adverse effects on individuals, groups and institutions because conflict resolution involves using up productive time and scarce resources, and diversion of energies that could more constructively be used elsewhere.

The review of the literature is also an indication that no or few studies has been done in Ghana to investigate the impact of conflict on productivity, such studies have neither been seen generally on organizations nor specifically on universities, hence the significance of this study.

\section{Data Issues and Methodology}

The main source of data for this study was the primary source and was drawn from the use of questionnaire which was the main instrument for gathering data for faculty members and interviews with selected administrative leadership. The population of this study included faculty and administrators in all public universities in Ghana. 
The choice of public universities for the study was because they are considered to be well established with rich experiences and have more complex and known organizational structures. The universities whose faculty and administrative leadership constitute the target population of this study are University of Ghana, Legon (UG), Kwame Nkrumah University of Science and Technology (KNUST), University of Cape Coast (UCC), University of Education, Winneba (UEW), University for Development Studies (UDS) and University of Mines and Technology (UMAT). The targeted administrative leaders in this study were Vice Chancellors/Pro-Vice-Chancellors/ Registrars/Deputy Registrars of Human Resource, Deans and Heads of Department/Units. The faculty included senior academic staff that have worked in their respective institutions for five years and above and have also applied for promotion at one time or another.

Purposive and random sampling techniques were used to select the study population. A sample of three (3) respondents was selected with respect to the administrative leaders of the selected universities. Thus, 18 administrative leaders of the 6 universities were sampled for the study. In selecting the sample of faculty for this study, a list of all faculty members and the number of years served were collected from the human resource offices of the public universities. The samples of faculty members who had served for more than five (5) years and had applied for promotion at one time or another were then drawn out from the list. A total of 249 faculty members were randomly selected for the study. Altogether, 267 participants were selected to take part in this study.

Based on the study's objective, this study used the quantitative approach of research. By this approach, the study used multiple regression to determine the relationship between promotion-related conflict and faculty productivity. In order to test whether there are significant differences in the mean scores on promotion-related conflicts and its effects on faculty productivity among the various Universities, a One-Way Anova and Kruskal Wallis Tests were also conducted.

\section{Results and Discussions}

\section{Institutional Distribution of Respondents}

Out of 249 questionnaires administered to faculty, 240 were retrieved during the survey. The response rate thus estimated to be $96.3 \%$. The result of the institutional distribution of the participants during the survey is illustrated in Table 1.

Table 1: Institutional Distribution of Participants in the Survey

\begin{tabular}{|l|l|l|}
\hline Institution & Number of Respondent & Percentage in sample (\%) \\
\hline UEW & 36 & 15.0 \\
\hline UCC & 44 & 18.3 \\
\hline UMAT & 30 & 12.5 \\
\hline KNUST & 40 & 16.7 \\
\hline UDS & 30 & 12.5 \\
\hline UG & 60 & 25.0 \\
\hline TOTAL & 240 & 100 \\
\hline
\end{tabular}

\section{Source: Author (Field Work)}

In terms of the institutional distribution of the respondents, 36 of the participants in the survey were from the University of Education, Winneba (UEW). This represented 15 percent of all respondent during the survey. 44 respondents were from the University of Cape Coast (UCC), $30(12.5 \%)$ of respondents were from the University of Mines and Technology (UMAT), 31(12.5\%) from the University for Development Studies (UDS). Also, 40 (16.7\%) of respondents were drawn of Kwame Nkrumah University of Science and Technology (KNUST). The University of Ghana (UG) also had 60 (25\%) respondents participating in the study.

\section{Age and Sex Distribution of Faculty}

In exploring the age and sex characteristics of the respondents, a cross-tabulation of age and sex was performed using SPSS. In terms of the sex distribution of the study Faculty participants, 176 (73.3\%) were males, whiles 64(26.7\%) were females. 
In relation to age however, the males consisted of $10(4.2 \%)$ faculty who were aged below 30 years, and $4(1.7 \%)$ who were aged between 31-40 years. In addition, $82(34.3 \%)$ and $80(33.3 \%)$ were in the age categories of 41-50 years and 51-60 years respectively.

Table 2: Age and Sex Distribution of Faculty

\begin{tabular}{|c|c|c|c|c|c|}
\hline & & & Sex & & Total \\
\hline & & & Male & \begin{tabular}{|c|} 
Female \\
\end{tabular} & \\
\hline & Below 30 years & Count & 10 & - & 10 \\
\hline & & $\%$ of Total & $4.2 \%$ & - & $4.2 \%$ \\
\hline & $31-40$ years & Count & 4 & 4 & 8 \\
\hline & & $\%$ of Total & $1.7 \%$ & $1.7 \%$ & $3.4 \%$ \\
\hline Age & 1) 50 mono & Count & 82 & 50 & 132 \\
\hline & th-ov years & $\%$ of Total & $34.2 \%$ & $20.8 \%$ & $55.0 \%$ \\
\hline & 5160 vom & Count & 80 & 10 & 90 \\
\hline & Ji-0o years & $\%$ of Total & $33.3 \%$ & $4.2 \%$ & $37.5 \%$ \\
\hline & & Count & 176 & 64 & 240 \\
\hline & & $\%$ of Total & $73.3 \%$ & $26.7 \%$ & $100.0 \%$ \\
\hline
\end{tabular}

Source: Author (Field Work)

The distribution of the 64 female faculty also showed that $4(1.7 \%), 50(20.8 \%)$ and $10(4.2 \%)$ fell within the age brackets of 31-40 years, 41-50 years and 51-60 years respectively. The result is illustrated in Table 2.

\section{Academic Qualification of Faculty}

With regards to the academic qualifications of the faculty who participated in this study, it was found that majority of them possess their master's degree. Specifically, $156(65 \%)$ of the academic faculty indicated that they have master's degree, while $72(30 \%)$ also indicated that they have obtained their doctoral degree. 12 of the faculty, representing 5\% of the participants, indicated that they have a post-doctoral qualification. The academic qualification of the participants is presented in Table 3 .

Table 3 Academic Qualification of Faculty

\begin{tabular}{lll}
\hline Qualification & Frequency & Percent (\%) \\
\hline Post-Doctoral & 12 & 5.0 \\
Doctoral Degree & 72 & 30.0 \\
Master's Degree & 156 & 65.0 \\
\hline Total & $\mathbf{2 4 0}$ & $\mathbf{1 0 0 . 0}$ \\
\hline
\end{tabular}

\section{Source: Author (Field Work)}

In assessing the effects of promotion-related conflicts on faculty productivity, faculty were asked to indicate their extent of agreement or disagreement to some statements in that respect. Variables were measured using a five point Likert scale. The outcomes of their responses were analysed descriptively and inferentially.

\section{Descriptive analysis of Effects of Conflict on Faculty productivity}

The responses to the question of the questionnaire used for the study to investigate the impact of conflict on faculty productivity were analysed descriptively by computing the mean and standard deviations. The result is presented in Table 4. 
It can be inferred from the result in Table 4 that, the overall mean sore for all the statements that the faculty responded to is 3.68 , while its corresponding standard deviation score is .499 . This result means that, broadly speaking, faculty were not sure about the overall effect of promotion related conflicts on faculty productivity. In addition, the low value of the standard deviation shows that the faculty have been very consistent in giving their responses to the various items. However, in considering the various variables individually, it was found that variables that suggested that promotionrelated conflicts could have negative influence on publication rate; performance review to help the institution and staff to plan for future contributions; and that it affect teaching attitude of faculty, received significantly higher ratings than the general result showed. Specifically, these variables had higher mean values of 4.12, 4.09, 3.99, and 3.91 respectively, which suggest that the faculty agree that each of them is an effect of promotion-related conflict on faculty

Table 4: Descriptive of Effects of promotion-related conflict on faculty productivity

\begin{tabular}{|l|l|l|}
\hline Statements N=240 & Mean & Std. Deviation \\
\hline Research behaviour & 3.85 & 1.03 \\
\hline Affect teaching attitude & 3.99 & .86 \\
\hline Holding on to information from students & 3.13 & 1.22 \\
\hline Withdrawal, absenteeism, and galamsey & 3.43 & 1.16 \\
\hline Hostility, uncompromising, sabotaging of efforts & 3.77 & 1.02 \\
\hline Influence publication rate & 4.12 & .71 \\
\hline Faculty evaluation to gather data to support institutional decisions & 3.91 & .72 \\
\hline $\begin{array}{l}\text { Affect Performance review that help the institution and staff to plan for } \\
\text { future contributions }\end{array}$ & 4.09 & .78 \\
\hline Total Mean & $\mathbf{3 . 6 8}$ & $\mathbf{. 4 9 9}$ \\
\hline
\end{tabular}

Sources: Author

More importantly, their respective mean deviation values were low, ranging from .71 to .86 , which indicate that the respondents exhibited high levels of consistency in their responses to these questions, though they were less consistent when compared to the result for the general group. The responses of the faculty to the remaining questions show that, just like the general result, they are not sure about their individual impact in terms of the productivity of faculty, as they observed mean values ranging between 3.12 and 3.43, while their standard deviation scores were also found to be high, hence an indication that the faculty were less consistent in giving their response to these questions. However, two of the remaining variables that border on the effects on research behaviour of faculty and also, hostility, uncompromising, sabotaging of efforts of faculty, recorded quite significant mean values of 3.85 and 3.77 respectively. However, in examining the various factors individually, it was realized that faculty through their responses agree that; promotionrelated conflict influence publication rate and the productivity of faculty; and that it affect teaching attitude of faculty.

\section{Inferential Analysis of Effects of promotion-related conflicts}

Inferential Analysis using One-Way Anova and Kruskal Wallis Test were conducted to determine whether there are significant differences in the mean scores on promotion-related conflicts and its effects on faculty productivity and achievement of institutional goals and mandates across the 6 universities. Post-hoc test was conducted where necessary to find out where these differences occur. When the conditions for One-Way Anova were not met, the Non-parametric Kruskal Wallis Test is adapted.

Prior to conducting the ANOVA, a test of Homogeneity of Variances was conducted to check whether the distributions did not violate the homogeneity condition required for the One Way Analysis of Variation. This is shown in Table 5 
Table 5: Test of Homogeneity of Variances of consequences of conflict on productivity

\begin{tabular}{|c|c|c|c|c|}
\hline & Levene Statistic & df1 & df2 & Sig. \\
\hline Research behaviour & 3.506 & 5 & 234 & .0 \\
\hline Affect teaching attitude & 2.823 & 5 & 234 & .017 \\
\hline $\begin{array}{l}\text { Holding on to information from } \\
\text { students }\end{array}$ & .662 & 5 & 234 & \\
\hline $\begin{array}{l}\text { Withdrawal, absenteeism, and } \\
\text { galamsey }\end{array}$ & .466 & 5 & 234 & \\
\hline $\begin{array}{l}\text { Hostility, uncompromising, } \\
\text { sabotaging of efforts }\end{array}$ & 2.488 & 5 & 234 & .03 \\
\hline $\begin{array}{l}\text { Influence publication rate and the } \\
\text { shape of faculty productivity curve }\end{array}$ & 1.318 & 5 & 234 & \\
\hline $\begin{array}{l}\text { Faculty evaluation helps to gather } \\
\text { data to support institutional } \\
\text { decisions }\end{array}$ & 6.679 & 5 & 234 & \\
\hline $\begin{array}{l}\text { Performance review is to help the } \\
\text { institution and staff to plan for } \\
\text { future contributions }\end{array}$ & 1.059 & 5 & 234 & \\
\hline
\end{tabular}

\section{Sources: Author}

Results of the Levene statistic with regards to the questions "Holding on to information from students (P-Value=.653)", "Withdrawal, absenteeism, and galamsey (P-Value=.802)", "Influence publication rate (P-Value=.257)" and "Affect Performance review that help the institution and staff to plan for future contributions (P-Value=.384)" with sampled public universities as category revealed that the distributions did not violate the homogeneity condition required for the One Way Analysis of Variation. The One-Way ANOVA results for these variables to determine if there is a statistically significant difference across the six universities is presented in Table 6.

Table 6: ANOVA results of effects of faculty conflicts on productivity

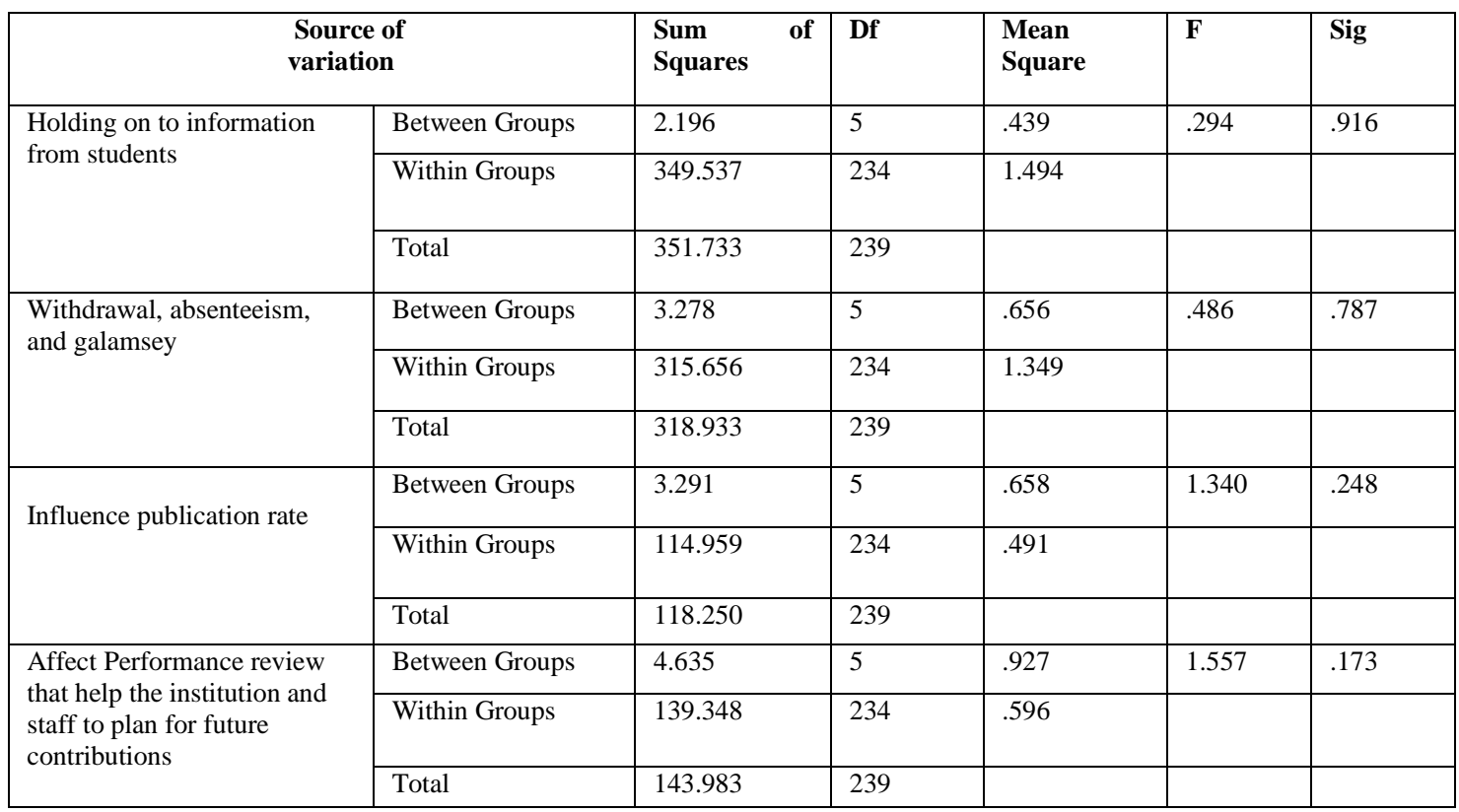

\section{Sources: Author}


ANOVA results depicted in Table 6 revealed that no statistical significant differences exist among universities selected for study on the variables "Holding on to information from students" ( $\mathrm{F}=.294$, P-value =.9169), "Withdrawal, absenteeism, and galamsey" $(\mathrm{F}=.486, \mathrm{P}$-value $=.787)$, "Influence publication rate" $(\mathrm{F}=1.340, \mathrm{P}$-value $=.248)$ and "Affect Performance review that help the institution and staff to plan for future contributions" $(\mathrm{F}=1.340$, $\mathrm{P}$-value $=.173)$. This finding shows that among all universities used for the study, it is perceived that Holding on to information from students, Withdrawal, absenteeism, and galamsey, Influence publication rate and Affect Performance review that help the institution and staff to plan for future contributions are effects of faculty promotion conflicts on faculty productivity. However, results of the Levene statistic in Table 5with regards to "Research behaviour (P-Value=.004)", "Affect teaching attitude (P-Value=.017)", "Hostility, uncompromising, sabotaging of efforts (P-Value=.032" and "Faculty evaluation to gather data to support institutional decisions $(\mathrm{P}-\mathrm{Value}=.000)$ " revealed a violation of the homogeneity condition. Hence, Kruskal Wallis Test was conducted to explore the statistically significant difference across the universities with respect to these variables. Results of the Kruskal Wallis Test are presented in Table 7.

Table 7: Kruskal Wallis Test Results of effects of conflict

\begin{tabular}{|c|c|c|c|}
\hline & Chi-square & Df & Asymp. sig \\
\hline Research behaviour & 10.918 & 5 & .053 \\
\hline Affect teaching attitude & 3.672 & 5 & .597 \\
\hline Hostility, uncompromising, sabotaging of efforts & 1.842 & 5 & .871 \\
\hline $\begin{array}{l}\text { Faculty evaluation to gather data to support } \\
\text { institutional decisions }\end{array}$ & 10.643 & 5 & .059 \\
\hline
\end{tabular}

\section{Source: Author}

The Kruskal Wallis Test results depicted in Table 7 reveals that there are no statistically significant differences across the 6 sampled university with respect to Research behaviour (Chi-square=10.918, P-Value=.053), Affect teaching attitude (Chi-square=3.672, P-Value=.597), Hostility, uncompromising, sabotaging of efforts $($ Chi-square $=1.842$, PValue $=.871$ and Faculty evaluation to gather data to support institutional decisions (Chi-square=10.643, P-Value $=.059$ ). This implies that across all the universities used for the study, it is perceived that Research behaviour, affect teaching attitude, Hostility, uncompromising, sabotaging of efforts, Faculty evaluation to gather data to support institutional decisions are effects of faculty promotion conflicts on faculty productivity.

A further analysis to investigate the extent of influence of the three variables that is, the faculty promotion modalities and procedures, the Nature of promotion-related conflict and the manner in which conflict is resolved on faculty productivity, using a multiple regression analysis with these three variables as independent variables and the dependent variable being faculty productivity. The following hypothesis was formulated for testing:

Ho: the faculty promotion modalities and procedures, the Nature of promotion-related conflict and the manner in which conflict is resolved do not influence Faculty productivity.

Ha: the faculty promotion modalities and procedures, the Nature of promotion-related conflict and the manner in which conflict is resolved significantly influence Faculty productivity.

In order to evaluate the model of regression, the ANOVA Table (Table 8) and Model Summary (Table 9) analysis were conducted and the results are presented below.

Table 8: ANOVA results of regression

\begin{tabular}{|ll|l|l|l|l|l|}
\hline Model & & Sum of Squares & Df & Mean Square & F & Sig. \\
\hline Regression & 63.025 & 22 & 2.865 & 14.436 & .000 \\
Residual & 43.063 & 217 & .198 & & \\
Total & 106.088 & 239 & & & \\
\hline
\end{tabular}

Source: Author

To assess the statistical significance of the result, the ANOVA Test results depicted in Table 8 is necessary to consider. This tests the null hypothesis that multiple $\mathrm{R}$ in the population is equal to zero. The model results depicted in Table 8 revealed that the model reaches statistical significance $(\mathrm{p}<.0005)$.

The statistical significance means that the variation explained by the model is not due to chance. The finding implies that the model explains a significant amount of variability. Also, Model Summary analysis was conducted to explore how much of the variance in the dependent variable is explained by the model. The Model Summary is presented in Table 9. 
Table 9: Model Summary of regression

\begin{tabular}{|c|c|c|c|c|}
\hline Model & $\mathrm{R}$ & R Square & $\begin{array}{|ll|}\text { Adjusted } & \mathrm{R} \\
\text { Square } & \\
\end{array}$ & Std. Error of the Estimate \\
\hline 1 & .771 & .594 & .553 & .44548 \\
\hline
\end{tabular}

The Model Summary results depicted in Table 9 indicate that the variance in the dependent variable (faculty productivity) is explained by the model. The value $\left(\mathrm{R}^{2}=0.594\right)$ indicates that almost $60 \%$ of the variability in the dependent variable observed could be predicted by the model (which includes, the faculty promotion modalities and procedures, the Nature of promotion-related conflict and the manner in which conflict is resolved on faculty productivity). The result therefore suggests that the model is adequate to predict the observed data.

Finally, in order to evaluate each of the independent variables included in the model contribution to the prediction of the dependent variable, a multiple regression coefficients results are presented in Table 10.

Testing for the significance of the model predictors is a necessary step in the use of the model for prediction. Comparing all the independent variables, Interpersonal tensions and cleavages $(B e t a=-.410)$ makes the strongest unique contribution to explaining the dependent variable (faculty productivity), when the variance explained by all other variables in the model is controlled for. However, Denial of deserved recognition (Beta $=-.005$ ) makes the lowest unique contribution to explaining the dependent variable. Concerning "Issues in the implementation of faculty promotion modalities (policies) and procedures", Approved policies are not disseminated to beneficiaries before they are implemented $($ Beta $=-.321)$ makes the strongest unique contribution whiles between policy and implementation are institutional structures that could be exploited (Beta=-.134) makes lowest unique contribution to explaining faculty productivity. Also, with respect to "Processing of Promotion Application Documents", Decision of Faculty Appointments and Promotions Committee (Beta=-.205) makes the strongest unique contribution whiles Processing of documents by institutional structures (Beta=-.025) makes lowest unique contribution to explaining faculty productivity. With regard to "Sources of Conflict", Interpersonal tensions and cleavages (Beta=-.410) makes the strongest unique contribution whiles denial of deserved recognition (Beta=-.025) makes lowest unique contribution to explaining faculty productivity.

Also, ten of independent variables, Approved policies are not disseminated to beneficiaries before they are implemented $(\mathrm{t}=-4.400, \mathrm{P}$-value $=.000)$, Academic board decisions on promotions are communicated to faculty on time $(\mathrm{t}=-2.695$, P-value $=.008)$, Documents that Faculty submits in support of promotion $(\mathrm{t}=-2.725, \mathrm{P}$-value=.007), Opposing interest disregarding that of the organization $(\mathrm{t}=--3.185$, $\mathrm{P}$-value=.002), Precedents are set to favour a few $(\mathrm{t}=-4.622, \mathrm{P}-$ value=.000), Manner decisions on application are communicated ( $\mathrm{t}=-3.399, \mathrm{P}$-value=.001), Faculty's attitude to source information on their promotion $(\mathrm{t}=-2.438$, P-value=.016), Grapevine information ( $\mathrm{t}=-2.369$, P-value=.019), Interpersonal tensions and cleavages $(\mathrm{t}=-5.741, \mathrm{P}-\mathrm{value}=.000)$ and Manner promotions related tensions and grievances are resolved ( $\mathrm{t}=-2.587, \mathrm{P}$-value=.010) make significant unique contribution to the prediction of the faculty productivity (dependent variable).

However, the following independent variables did not make significant contributions towards predicting of faculty productivity (dependent variable): Between policy and implementation are institutional structures that could be exploited ( $\mathrm{t}=-1.752$, P-value=.081) Differing values that will not allow people to compromise $(\mathrm{t}=1.558$, $\mathrm{P}$-value $=.081)$, Poor communication $(\mathrm{t}=1.846, \mathrm{P}$-value $=.066)$, Denial of deserved recognition $(\mathrm{t}=-.235$, $\mathrm{P}$-value $=.814)$, Examiners undue delay in evaluating promotion documents $(\mathrm{t}=-1.391$, P-value $=.166)$, Processing of documents by institutional structures $(\mathrm{t}=.074, \mathrm{P}$-value $=.941)$, Promotion policies take retrospective effects $(\mathrm{t}=.299, \mathrm{P}$-value $=.164)$ and Differing values that will not allow people to compromise $(\mathrm{t}=.632$, P-value $=.528$. $)$ This may be due to overlap with other independent variables in the model. 
Table 10: Coefficients from Regression Analysis (Dependent is faculty productivity)

\begin{tabular}{|c|c|c|c|c|c|c|}
\hline \multirow{2}{*}{\multicolumn{2}{|c|}{ Model }} & \multicolumn{2}{|c|}{$\begin{array}{l}\text { Unstandardized } \\
\text { Coefficients }\end{array}$} & \multirow{2}{*}{\begin{tabular}{|l|}
$\begin{array}{l}\text { Standardized } \\
\text { Coefficients }\end{array}$ \\
Beta
\end{tabular}} & \multirow[t]{2}{*}{$\mathrm{T}$} & \multirow[t]{2}{*}{ Sig. } \\
\hline & & $\mathrm{B}$ & Std. Error & & & \\
\hline & (Constant) & .684 & .461 & & 1.482 & .140 \\
\hline & \multicolumn{6}{|c|}{ Issues in the implementation of faculty promotion modalities (policies) and procedures } \\
\hline & $\begin{array}{l}\text { Gaps in promotion policies and } \\
\text { procedures allow exploitation in the } \\
\text { processing of promotion application }\end{array}$ & -.129 & .074 & -.134 & -1.752 & .081 \\
\hline & $\begin{array}{l}\text { Approved policies are not } \\
\text { disseminated to beneficiaries before } \\
\text { they are implemented }\end{array}$ & -.188 & .043 & -.321 & -4.400 & .000 \\
\hline & $\begin{array}{l}\text { Promotion policies take retrospective } \\
\text { effects }\end{array}$ & -.073 & .047 & -.144 & -1.558 & .121 \\
\hline & $\begin{array}{l}\text { Academic board decisions on } \\
\text { promotions are not communicated to } \\
\text { faculty on time }\end{array}$ & -.120 & .045 & -.192 & -2.695 & .008 \\
\hline & \multicolumn{6}{|c|}{ Processing of Promotion Application Documents } \\
\hline & $\begin{array}{l}\text { Documents that Faculty submits in } \\
\text { support of promotion }\end{array}$ & -.091 & .034 & -.165 & -2.725 & .007 \\
\hline & $\begin{array}{l}\text { Decision of Faculty Appointments } \\
\text { and Promotions Committee }\end{array}$ & -.125 & .068 & -.205 & -1.846 & .066 \\
\hline & $\begin{array}{l}\text { Processing of documents by } \\
\text { institutional structures }\end{array}$ & .014 & .058 & -.025 & .235 & .814 \\
\hline & $\begin{array}{l}\text { Examiners undue delay in evaluating } \\
\text { promotion documents }\end{array}$ & .048 & .034 & .116 & 1.391 & .166 \\
\hline & \multicolumn{6}{|l|}{ Sources of Conflict } \\
\hline & Denial of deserved recognition & -.003 & .044 & -.005 & -.074 & .941 \\
\hline & $\begin{array}{l}\text { Opposing interest disregarding that } \\
\text { of the organization }\end{array}$ & -.144 & .045 & -.192 & -3.185 & .002 \\
\hline & $\begin{array}{l}\text { Differing values that will not allow } \\
\text { people to compromise }\end{array}$ & .026 & .042 & .033 & .632 & .528 \\
\hline & Precedents are set to favour a few & -.148 & .032 & -.253 & -4.622 & .000 \\
\hline & $\begin{array}{l}\text { Manner decisions on application are } \\
\text { communicated }\end{array}$ & -.140 & -.041 & .184 & -3.399 & .001 \\
\hline & $\begin{array}{l}\text { Faculty's attitude to source } \\
\text { information on their promotion }\end{array}$ & -.083 & .034 & -.140 & -2.438 & .016 \\
\hline & Grapevine information & -.140 & .059 & -.181 & -2.369 & .019 \\
\hline & Interpersonal tensions and cleavages & -.346 & .060 & -.410 & -5.741 & .000 \\
\hline & $\begin{array}{l}\text { Manner promotion- related tensions } \\
\text { and grievances are resolved }\end{array}$ & -.113 & .044 & -.149 & -2.587 & .010 \\
\hline
\end{tabular}

\section{Source: Author}

The effect of significant variables can be interpreted in terms of their magnitude and sign of the coefficients of the predictors. A high perceived productivity will be experienced as a result of a high level of fairness with regard to faculty promotion. In specific interpretation of the coefficient of each predictor variable will depend on the values of other variables being fixed since there are more than one predictor variable in the model.

In summary, the results of the model support the hypothesis, the faculty promotion modalities and procedures, the Nature of promotion-related conflict and the manner in which conflict is resolved significantly influences Faculty productivity in Ghanaian Public Universities. Key among predictor variables were Interpersonal tensions and cleavages $(\beta=-.346)$ and Approved policies are not disseminated to beneficiaries before they are implemented $(\beta=-0.188)$ which had the largest effect on the faculty productivity.

\section{Comments on Faculty promotion-related conflicts and their effects}

An open ended question in the questionnaire which demanded faculties to comment on any other issues related to Faculty promotion-related conflicts and their effects on faculty commitment and productivity, provided the following responses discussed below. 
One faculty asserted that "when an applicant raises a counter view, he is mostly seen as a threat and an enemy. Such an individual is side lined or avoided and he resists getting on board or fails to cooperate because he is peeved" (Faculty 49). Another faculty also indicated that the "seeming discrimination against some faculty members of staff who genuinely qualify in favour of others is a stab in the back of the university and this promotes mediocrity" (Faculty 11). These comments will suggest that the effects of promotion-related conflicts go beyond faculty productivity, to generating social tensions including hostility and victimization. The suggestion is that, some staff are mostly seen as trouble makers; and are side-lined or avoided. The implication is that some faculty members may be denied promotion although they may genuinely qualify for promotion. Alternatively, some who may not have qualified maybe promoted based on cronyism. Also, the comments indicated that some individuals who are victimized get to withdraw whether formally or informally from accepting to perform certain roles within the institution, usually by resisting appointments to some positions and refuse to be team players.

\section{Major Findings and Discussions}

The results of the study revealed that faculty promotion-related conflicts and the manner in which they are resolved affect the following measures of productivity in HEI: Research behaviour, teaching attitude, hostility, uncompromising, sabotaging of efforts, Influence publication rate and affect performance review that help the institution and staff to plan for future contributions.

The findings that promotion-related conflicts influence publication rate bespeaks how conflicts affect productivity in negative ways. As Mankoe (2007) explained, conflict has negative effects on institutional performance depending on the nature of the conflict and how it is resolved. Some researchers also explained that conflict can have a devastating impact on the behaviour of people, develops into hostility, physical withdrawal and turnover, alienation, apathy and indifference among people involved as well as general weakening of relationship among groups and on individuals.

This further makes the point advanced by Nelson-Jones (1995) and Owens (2001) that conflicts within any institution can have negative effects on productivity of the institution. The effects suggest, as argued by writers including Pylee and George (2009) that even one discontented employee nursing a grievance can eventually infect an entire institution resulting in lower efficiency and poor morale and reduction in overall production.

The results of the model to test for significance support the hypothesis: faculty promotion modalities and procedures, Nature of promotion-related conflict and the manner in which conflict is resolved significantly influence Faculty productivity in Ghanaian Public Universities. Key among predictor variables were: Interpersonal tensions and cleavages, Approved policies are not disseminated to beneficiaries before they are implemented and manner tensions and conflicts are resolved had the largest effects on faculty productivity.

\section{Conclusions and Recommendations}

The study sought to investigate the impact of faculty promotion-related conflict as well as their resolution on faculty productivity in Public Universities in Ghana. Relying on quantitative approach of research, the study used multiple regression to determine the relationship between promotion-related conflict and faculty productivity, conducted a OneWay ANOVA and a Kruskal Wallis Tests to find out whether there are significant differences in the mean scores on promotion-related conflicts and its effects on faculty productivity across the various Universities. The major finding was that promotion-related conflict in higher education institutions has negative effects on both faculty and institutional performance depending on the nature of the conflict and how it is resolved.

The findings of this study suggest that administrators, policy makers and faculty members should have keen interest in Faculty-promotion policies and conflicts since it has great impact on faculty productivity and the overall institutional productivity. It is therefore, incumbent on policy makers including National Centre for Tertiary Education (NCTE), Academic Board and University Management to ensure explicit and comprehensive promotion policies and guidelines. Specifically, it is important that the NCTE and Universities have a systematic and sustainable process of organizing seminars, workshops and conferences, on sustainable basis, to discuss conflict resolution in general and promotionrelated conflicts in particular. Also, University Management/Administration should provide promotion guidelines including the criteria for promotion assessment to all staff and ensure that workshops are organized to educate staff on the content and promotions process. Finally, faculty members should take time to ensure that they are well educated on the promotion process and the requirements for promotion.

\section{References}

Aldag R. J., Stearns T.M. (1987), Management, South-Western Publishing Co. Cincinnati, Ohio, USA. 
Allen, N. (1988). Aspect of promotion procedures in Australian University: Higher education (17:267-280). Kluwer Academic Publishers, Dordrecht.

Barker, F. \& Gum, L. (1994). Discipline in schools. West Chicago: Hove Press. p. 67170.

Bilson, A. (2000). Framework for situation analysis of children deprived of parental care. Geneva: UNICEF CEE/CIS/ Baltics Regional Office. Biggs

Burton, J W. (1990). Conflict: Practices in Management, Settlement and Resolution. London: Macmillan and New York: St. Martin's Press.

Burton, J. W. (1990) Conflict: Resolution and prevention. New York: St Martin's Press.

Clue L (2013) Structural Equation Modelingwith Amos: Basic Concepts, Applications, and Programming.

Deutsch, M. (1973). The resolution of conflict. New Haven, CT: Yale University Press.

Gappa, J. M., Austin, A. E., \& Trice, A. G. (2007) Rethinking Faculty Work: Higher Education's Strategic Imperative. an Francisco: John Wiley and Sons

Hart,S (2002)“Beyond Greening: Strategies for a Sustainable World, "Harvard Business Review,Hastings, R. (2007). "Conflict management contribute to communication." SHRM Online Diversity Focus, January 2007. 3 September, 2007. Retrieved from www.shrm.org on $2^{\text {nd }}$ April, 2013.

Hearn, J. C., \& Anderson, M. S. (2002). Faculty demography: Exploring the effects of seniority distributions in universities. In: Smart, J. C. (ed.), and Higher Education: Handbook of Theory and Research (Vol. XIII), Agathon, New York, pp. 235-273.

Hellriegel, D., Slocum, J.-W., \& Woodman, R.-W. (1992). Organizational Behaviour, (6th ed.), New York: West Publishing Company.

Kczynski P. (2002) Communities of cooping, collective and emotional labour in service work organization 10, 1, 55-79

Kittlaus, S \& Leas, S, (1978). New Ways of Managing Conflict, New York NY: McGraw-Hill, 1973.

Mankoe, J. O. (2007). Educational administration and management in Ghana. Madina-Accra: Progressive Stars Limited.

Mills, M., \&Hyle, A. (1999). Faculty evaluation: A prickly pear. Higher Education, 38, 351371.Retrieved March 15, 2004, from EBSCOHost database.

Nelson-Jones, R. (1995). Danışmapsikolojisikuramları, Ankara: Cassell Education.

Oforiwaa, O. \& Afful-Broni A. (2014). Gender and promotions in higher education: A case study of the University of Education, Winneba, Ghana. International Journal of Education Learning and Development 2 (1) 34-47. www.ea-Journals.org. Retrieved on 3rd February, 2015.

Owens, R. G. (2001). Organisational behavior in education. Needham Heights. MA: Allyn and Bacon.

Owens, R.G. (1987). Organizational behavior in education. Englewood Cliffs, N.J.: Prentice-Hall.

Pylee, M. V. \& George, A. S. (2009). Industrial relations and personnel management ( $3^{\text {rd }}$ ed.). New Delhi: Vikas Publishing House.

Schnake, M. E. (1987). Principle of supervision. Dubugne, IOWA: Win C. Brown Publishers.

Thomas, K. (1976). Conflict and conflict management. In W.K. Hoy and C.G. Miskel (Eds.), Educational Administration: Theory, Research, Practice (pp. 100-102). New York:McGraw-Hill, 1991.

Tien F.F \&Blackburn R.T (1996) Faculty Rank System, Research Motivation, a Faculty Research Productivity: Measure Refinement and Theory Testing.

Wright, P. \&Noe, R. (1996). Management of organisations, Irwin. 